\title{
Cost-Minimization Analysis of Once-Weekly Versus Thrice-Weekly Epoetin Alfa for Chemotherapy-Related Anemia
}

\author{
PIERRE Y. CRÉMIEUX, PhD; JOHN M. FASTENAU, RPh, MPH; GEORGE KOSICKI, PhD; \\ CATHERINE T. PIECH, MBA; and A. MARK FENDRICK, MD
}

\begin{abstract}
BACKGROUND: For individuals with chemotherapy-related anemia, the clinical effectiveness of epoetin alfa (EPO) dosed once weekly ([QW], 40,000 units per dose) has been demonstrated to be indistinguishable from that observed with thrice-weekly dosing ([TIW], 10,000 units per dose). Whether the advantage of less-frequent administration justifies the higher EPO dosage used in the weekly regimen in terms of overall cost of care is unknown.
\end{abstract}

OBJECTIVE: To conduct a cost-minimization analysis comparing QW and TIW EPO dosing from a societal perspective.

METHODS: Direct and indirect medical cost data were calculated for a 16-week period for 2 large, prospective, multicenter, community-based studies. Costs measured included EPO, transfusions, laboratory tests, office visits, and opportunity cost of patient time.

RESULTS: The average total costs in 2002 (first half) dollars were nearly equivalent across the 2 groups (QW: $\$ 9,204 ; 95 \%$ confidence interval [Cl], \$9,057$\$ 9,350$. TIW: $\$ 9,265 ; 95 \% \mathrm{Cl}, \$ 9,083-\$ 9,447$. $P=0.60$ ). QW incurred mean drug acquisition costs that were $23 \%$ higher (QW: \$6,725; 95\% Cl, \$6,611-\$6,838. TIW: \$5,474; 95\% Cl, \$5,350-\$5,598. $P<0.001$ ). However, QW patients can avoid the resource use and time cost associated with 2 additional office visits incurred each week (QW: \$592 [\$583-\$600]; TIW: \$1,709 [\$1,678-\$1,740]; $P<0.001$ ). Transfusion and laboratory test costs were slightly higher in the TIW group (QW: \$1,888 [\$1,837-\$1,940]; TIW: \$2,082 [\$2,020-\$2,144]; $P<0.001$ ).

CONCLUSION: Total anemia treatment costs over a 16-week period with EPO QW were similar to those of TIW dosing. In the absence of cost differences between regimens, the noneconomic advantages of less-frequent dosing intervals should make weekly dosing increasingly attractive to patients, clinicians, and payers.

KEYWORDS: Epoetin alfa, Chemotherapy-related anemia, Cancer, Thrice-weekly dosing, Once-weekly dosing, Cost-effectiveness

J Manag Care Pharm. 2004;10(6):531-37

\section{Authors}

PIERRE Y. CRÉMIEUX, PhD, is a managing principal, Analysis Group, Inc. Boston, and is an adjunct professor, Department of Economics, University of Québec at Montreal, Canada; JOHN M. FASTENAU, RPh, MPH, is a director and CATHERINE T. PIECH, MBA, is executive director, Outcomes Research, Clinical Affairs, Ortho Biotech Products, L.P., Bridgewater, New Jersey; GEORGE KOSICKI, $\mathrm{PhD}$, is vice president, Analysis Group, Inc., Boston; A. MARK FENDRICK, MD, is a professor, Division of General Medicine, Department of Internal Medicine, University of Michigan School of Medicine, Ann Arbor.

AUTHOR CORRESPONDENCE: Pierre Y. Crémieux, PhD, Managing Principal, Analysis Group, Inc., 111 Huntington Ave., Tenth Fl., Boston, MA 02199-7636. Tel: (617) 425-8135; Fax: (617) 425-8001; E-mail: pcremieux@analysisgroup.com Copyright $\odot$ 2004, Academy of Managed Care Pharmacy. All rights reserved. nemia incidence and symptoms increase with greater $\triangle$ use of dose-dense and dose-intense chemotherapy 1 regimens for cancer management. ${ }^{1}$ The adverse consequences of anemia symptoms on a patient's well-being and ability to perform daily activities have been demonstrated. ${ }^{2-6}$ Large, prospective, community-based studies have also shown improvements in quality of life associated with increased hemoglobin or hematocrit levels in cancer patients following the administration of recombinant human erythropoietin (epoetin alfa [EPO], Procrit), which were independent of disease response to chemotherapy., ${ }^{4-6}$ Guidelines published by the American Society of Hematology and the National Comprehensive Cancer Network indicate that patients with hemoglobin levels below $12.0 \mathrm{~g} / \mathrm{dL}$ and $11.0 \mathrm{~g} / \mathrm{dL}$, respectively, are indicated for treatment with EPO. ${ }^{10,11}$ Medicare will reimburse treatment of chemotherapyrelated anemia with EPO if, among other requirements, the treatment target is $12 \mathrm{~g} / \mathrm{dL}$ or a hematocrit of $36 \%(13.0 \mathrm{~g} / \mathrm{dL})$ or $39 \%$ in the case of severe comorbidities. ${ }^{12}$

Evidence from community-based clinical trials suggests that the standard EPO regimen of 10,000 units administered subcutaneously thrice weekly (TIW) can be substituted with a dose of 40,000 units administered subcutaneously once weekly (QW) with no reduction in clinical effectiveness in terms of hemoglobin increase or improvement in quality of life (Table 1 summarizes EPO administration guidelines). ${ }^{6,13}$ In addition, similar responses in clinical effectiveness were observed in a recent EPO QW trial. ${ }^{14}$ Moreover, the logistical advantages of the weekly regimen are likely to enhance the feasibility of anemia treatment to patients (and families) initially unwilling to commit to the TIW regimen.

Although the clinical and logistical advantages of a switch from a TIW to a QW regimen may seem obvious, the potential economic ramifications of this substitution need to be carefully assessed. Because the weekly regimen requires an additional 10,000 units of EPO per week, a rigorous analysis is warranted to assess whether the advantages attributable to the more convenient regimen are worth the incremental expenditure on EPO. Although the cost-effectiveness of a TIW regimen of EPO for patients with chemotherapy-related anemia has been established, limited data are available on the cost-effectiveness of a QW dosing. ${ }^{15}$ More importantly, there are no published analyses comparing the cost implications of the QW regimen, the current standard of care, with the TIW regimen. ${ }^{11,16-18}$ Accordingly, the primary objective of this analysis was to compare the direct and indirect costs associated with QW and TIW EPO therapy for individuals with chemotherapy-related anemia. 


\begin{tabular}{|c|c|c|c|}
\hline & Initial Doses Discussed & $\begin{array}{l}\text { Maximum Hb Level at Which } \\
\text { Treatment With Epoetin } \\
\text { Alfa Should Be Initiated }\end{array}$ & $\begin{array}{l}\text { Time Point and Hb Threshold } \\
\text { for Dose Escalation }\end{array}$ \\
\hline $\begin{array}{l}\text { American Society of Hematology/ } \\
\text { American Society of Clinical } \\
\text { Oncology }^{10}\end{array}$ & $\begin{array}{l}150 \text { U/kg TIW } \\
40,000 \text { U QW }\end{array}$ & $12.0 \mathrm{~g} / \mathrm{dL}$ & $\begin{array}{l}\text { Escalate at } 4 \text { weeks if } \mathrm{Hb} \\
\text { change from baseline }<1.0 \mathrm{~g} / \mathrm{dL}\end{array}$ \\
\hline $\begin{array}{l}\text { National Comprehensive } \\
\text { Cancer Network }^{11}\end{array}$ & $\begin{array}{l}10,000 \text { U TIW } \\
150 \text { U/kg TIW } \\
40,000 \text { U QW }\end{array}$ & $11.0 \mathrm{~g} / \mathrm{dL}$ & $\begin{array}{l}\text { Escalate at } 4 \text { weeks if } \mathrm{Hb} \\
\text { change from baseline }<1.0 \mathrm{~g} / \mathrm{dL}\end{array}$ \\
\hline \multirow[t]{2}{*}{ FDA-labeled dose } & 150 U/kg TIW & Not specified & $\begin{array}{l}\text { Escalate at } 8 \text { weeks if } \mathrm{Hb} \\
\text { change from baseline }<1.0 \mathrm{~g} / \mathrm{dL}\end{array}$ \\
\hline & $40,000 \mathrm{U}$ QW & Not specified & $\begin{array}{l}\text { Escalate at } 4 \text { weeks if } \mathrm{Hb} \\
\text { change from baseline }<1.0 \mathrm{~g} / \mathrm{dL}\end{array}$ \\
\hline
\end{tabular}

\section{Methods}

\section{Data Sources}

Two large, open-label, community-based clinical studies evaluating, respectively, TIW $(n=2,198)$ and QW $(n=2,856)$ EPO therapies were used as the primary data sources (Table 2) ${ }^{4,6}$ The patients in each study were anemic (hemoglobin $\leq 11 \mathrm{~g} / \mathrm{dL}$ ) and received cisplatin-based or non-cisplatin-based chemotherapy, with or without radiation therapy. These patients presented with a variety of tumor types. The primary difference between the trials was the protocol for EPO administration.

In the TIW study, patients initially received a dose of 10,000 units 3 times per week. If a patient's hemoglobin concentration did not increase by at least $1 \mathrm{~g} / \mathrm{dL}$ by week 4 , the dosage was increased to 20,000 units TIW. In the QW study, patients were initially given a dose of 40,000 units per week. If a patient did not experience an increase in hemoglobin concentration of $1 \mathrm{~g} / \mathrm{dL}$ or greater by week 4, the dose was increased to 60,000 units per week. In both trials, treatment was discontinued if, after 8 weeks, change in hemoglobin concentration was less than $1 \mathrm{~g} / \mathrm{dL}$. The U.S. Food and Drug Administration-labeled doses for EPO are 150 units per $\mathrm{kg}$ TIW, with escalation at week 8 to 300 units per kg TIW in the event of nonresponse, and 40,000 units QW, with escalation at week 4 to 60,000 units QW in the event of nonresponse. The 40,000 QW regimen is commonly used. ${ }^{11}$

Patients with at least 1 recorded dose of EPO, a nonmissing baseline hemoglobin reading of less than or equal to $11 \mathrm{~g} / \mathrm{dL}$ as required by the protocol, and sufficient data to evaluate hemoglobin response (i.e., at least 1 hemoglobin reading after the baseline) were included in this analysis. Comparison of the end points of each trial demonstrates similar hemoglobin and quality-of-life responses for the TIW and QW EPO dosing schedules. ${ }^{4,6}$ While the proportion of patients receiving transfusions differed between the 2 trials (31\% of TIW patients received transfusions compared with $25 \%$ of QW patients), more patients in the TIW trial were transfused before the start of EPO therapy (29\% of TIW patients compared with $22 \%$ of QW patients $)^{4,5}$ The proportions of patients with a dose escalation were similar between the 2 studies: $36.7 \%$ of TIW patients received a dose of 20,000 units or greater, and $33.4 \%$ of QW patients received a dose of 60,000 units or greater at any time. Response rates were also similar between the 2 trials, with $65.8 \%$ of TIW patients and $68 \%$ of QW patients experiencing a $2 \mathrm{~g} / \mathrm{dL}$ rise in hemoglobin, or a hemoglobin level that is greater than or equal to $12 \mathrm{~g} / \mathrm{dL}$ at some point in the study in the absence of a transfusion. ${ }^{4,5}$ Patients in the 2 trials withdrew and experienced adverse events at similar rates (Tables 3 and 4).

\section{Cost-Minimization Analysis}

If 2 interventions document the same clinical outcome, a comparative economic evaluation can be conducted as a cost-minimization analysis. ${ }^{19,20}$ In both of the EPO-effectiveness studies, resource utilization data were reported for EPO, transfusions, laboratory tests, office visits, and opportunity cost of patient-time resources over the period during which patients remained in the studies. Costs were approximated by applying cost estimates of specific procedures from published literature to the utilization observed for each patient in each trial. Because the use of EPO was well defined in time and limited to patients with cancer who were undergoing chemotherapy, intervention boundaries were easily identified. The relatively short duration of the treatment period makes discounting costs unnecessary (mean treatment durations appear in Table 2; "discounting" refers to the practice in financial analysis of adjusting future cash flows to reflect the time value of money). The assumptions that were made regarding cost and utilization for both studies are summarized in Table 5. When cost assumptions gathered from the literature (e.g., cost of transfusion, EPO concentration, 
TABLE 2 Study and Baseline Characteristics of Community-Based Clinical Trials

\begin{tabular}{|c|c|c|c|}
\hline & $\begin{array}{c}\text { TIW } \\
(\mathrm{N}=2,198)\end{array}$ & $\begin{array}{c}\text { QW } \\
(\mathrm{N}=2,856)\end{array}$ & $P$ Value $*$ \\
\hline Selected Eligibility Requirements & \multicolumn{3}{|c|}{$\begin{array}{l}\text { Nonmyeloid Malignancy, Anemia }(\mathrm{Hb} \leq 11.0 \mathrm{~g} / \mathrm{dL}) \text {, Concomitant Chemotherapy, } \\
\text { Iron Supplementation, and Life Expectancy } \geq 24 \text { Weeks }\end{array}$} \\
\hline Mean treatment duration (weeks) (range) & $12.9(2-26)$ & $12.2(0-24)$ & 0.000 \\
\hline Dosage adjustment allowed? & Yes & Yes & \\
\hline Starting epoetin alfa dosage & 10,000 U TIW & $40,000 \mathrm{U}$ QW & \\
\hline Mean epoetin alfa dose (range) & $35,360(2,143-69,370) \mathrm{U}$ & $43,187(20,000-63,750) \mathrm{U}$ & \\
\hline \multicolumn{4}{|l|}{ Baseline characteristics } \\
\hline \multicolumn{4}{|l|}{ Gender (\%) } \\
\hline Men & 39.5 & 36.5 & 0.029 \\
\hline Women & 60.5 & 63.5 & \\
\hline Mean age (years) & 63.3 & 63.1 & 0.627 \\
\hline Initial hemoglobin (g/dL) & 9.3 & 9.5 & 0.000 \\
\hline Initial hematocrit (\%) & 27.8 & 28.4 & 0.000 \\
\hline Baseline QOL (LASA overall) & 45.7 & 46.6 & 0.166 \\
\hline $\begin{array}{l}\% \text { of patients transfused within } \\
6 \text { months prior to study }\end{array}$ & 28.8 & 22.1 & 0.000 \\
\hline$\%$ of patients transfused while on study & 30.5 & 24.8 & 0.000 \\
\hline \multicolumn{4}{|l|}{ Chemotherapy regimens } \\
\hline Cisplatin-containing (\%) & 15.7 & 10.8 & 0.000 \\
\hline Carboplatin-containing (\%) & 19.3 & 22.2 & 0.013 \\
\hline $\begin{array}{l}\text { Both cisplatin- and } \\
\text { carboplatin-containing (\%) }\end{array}$ & 1.6 & 1.2 & 0.222 \\
\hline Non-platinum-containing (\%) & 63.4 & 65.8 & 0.075 \\
\hline Patients receiving radiotherapy (\%) & 13.6 & 13.4 & 0.814 \\
\hline \multicolumn{4}{|l|}{ Primary tumor type } \\
\hline Hematologic (\%) & 21.1 & 16.0 & 0.000 \\
\hline Nonhematologic (\%) & 79.1 & 84.0 & 0.000 \\
\hline Lung† (\%) & 30.7 & 31.1 & 0.790 \\
\hline Breast $\dagger(\%)$ & 21.4 & 22.2 & 0.548 \\
\hline Gynecologic $†$ (\%) & 16.2 & 15.3 & 0.421 \\
\hline Gastrointestinal $\dagger(\%)$ & 11.5 & 18.2 & 0.000 \\
\hline Other† (\%) & 20.2 & 13.2 & 0.000 \\
\hline \multicolumn{4}{|c|}{$\begin{array}{l}\text { * P values of } t \text { tests comparing mean age, initial hemoglobin, initial hematocrit, and baseline } Q O L \text { across the } 2 \text { samples, and probabilities of chi-square tests comparing } \\
\text { gender, percentage of patients transfused, chemotherapy regimens, and primary tumor types across the } 2 \text { samples. } \\
+ \text { Percentages of each nonhematologic tumor type are calculated within the sample of patients with at least } 1 \text { nonhematologic tumor. } \\
\text { TIW = community study using thrice weekly therapy; QW = community study using once-weekly therapy; QOL = quality of life; LASA = Linear Analog Scale } \\
\text { Assessment. }{ }^{4,6} \\
\text { Note: These are the observations with at least } 1 \text { recorded dose of epoetin alfa, a nonmissing baseline hemoglobin value less than or equal to } 11.0 \mathrm{~g} / \mathrm{dL} \text { as required by the } \\
\text { protocol, and data to evaluate hemoglobin response. }\end{array}$} \\
\hline
\end{tabular}

complete blood count, cost of office visit) were not contemporaneous, costs were corrected for inflation using the Consumer Price Index for Medical Care Services. All costs were expressed in 2002 (first half) U.S. dollars. Cost components measured were EPO, transfusions, laboratory tests, and time (physician fees plus the opportunity cost of patient time). Drug costs were calculated by multiplying the cumulative dose by the 2002 average wholesale price. ${ }^{21}$ The cumulative dose was calculated as the sum of the mean weekly EPO dose observed over the study period. The costs of syringes, alcohol swabs, and other 
medical supplies were not considered because they are included in the outpatient procedure costs and would thus be counted twice.

\section{Statistics}

Costs were calculated for each patient in the 2 studies. These patient-specific costs were averaged across patients within each sample, and the means were compared using standard $t$ tests; 95\% confidence intervals (CIs) around the point estimates of the mean costs were also constructed. For all tests, $P$ was considered statistically significant when it was less than 0.05 .

Sensitivity analyses were conducted by varying the values of cost drivers and testing for statistically significant differences in TIW and QW mean total costs. For each cost driver, the percentage change that led to a statistically significant difference between the total costs of TIW and QW was also identified. All analyses were performed using SAS software version 8.00 (SAS Institute, Cary, North Carolina).

\section{Results}

\section{Cost per Patient Treated}

The overall mean cost per patient treated was similar for both the TIW and QW regimens: $\$ 9,265$ in 2002 U.S. dollars (95\% CI, \$9,083-\$9,447) for TIW and \$9,204 (95\% CI, \$9,057$\$ 9,350)$ for $\mathrm{QW}(P=0.60)$. Cost components for each of the regimens are shown in Table 6 . Transfusion and laboratory test costs were lower for the QW regimen. Also, QW patients have significantly lower time costs, which are attributable to 2 fewer office visits each week: $\$ 1,709$ (95\% CI, $\$ 1,678-\$ 1,740)$ for TIW treatment as compared with \$592 (95\% CI, \$583-\$600) for QW treatment $(P<0.001)$. These lower costs for the QW regimen were offset by the higher EPO dose required by QW patients compared with the weekly dosage for TIW patients: $\$ 5,474$ (95\% CI, $\$ 5,350-\$ 5,598)$ for TIW and $\$ 6,725$ (95\% CI, $\$ 6,611$ - $\$ 6,838)$ for QW $(P<0.001)$. Average weekly dose was 35,360 units (95\% CI, 34,990-35,730 units) for TIW patients and 43,187 units (95\% CI, 42,945 -43,429 units) for QW patients.

\section{Sensitivity Analysis}

The sensitivity analysis in Table 6 shows that the total cost of the QW regimen remains close to the total cost of the TIW regimen under a range of assumptions. Higher-than-average fees for office visits or for the opportunity cost of time raise the cost of the TIW regimen above that of the QW regimen and eventually lead to the QW regimen's being statistically less costly. Very low values for physician fees or the opportunity cost of time yield the opposite results; the TIW regimen becomes statistically less costly. Ten-percent changes in the cost of EPO or in the cost of blood do not affect the statistical results. Table 6 also shows the percentage changes in cost of drugs, physician fees, transfusion costs, opportunity costs, and visits per

\begin{tabular}{|c|c|c|}
\hline Evaluable Patients & $\begin{array}{c}\text { TIW } \\
2,198\end{array}$ & $\begin{array}{c}\mathrm{QW} \\
2,856\end{array}$ \\
\hline Week & $\mathrm{N}$ (Cumulative \%) & $\mathrm{N}$ (Cumulative \%) \\
\hline 2 & $18(0.8)$ & $94(3.3)$ \\
\hline 4 & $118(5.4)$ & $299(10.5)$ \\
\hline 6 & $266(12.1)$ & $435(15.2)$ \\
\hline 8 & $402(18.3)$ & $677(23.7)$ \\
\hline 10 & $690(31.4)$ & $832(29.1)$ \\
\hline 12 & $853(38.8)$ & $1,033(36.2)$ \\
\hline 14 & $1,063(48.4)$ & $1,204(42.2)$ \\
\hline 16 & $1,262(57.4)$ & $2,133(74.7)$ \\
\hline
\end{tabular}

TIW = community study using thrice-weekly therapy;

QW = community study using once-weekly therapy.

\section{TABLE 4 Adverse Events Reported in at Least $2 \%$ of Patients}

\begin{tabular}{|c|c|c|c|c|c|}
\hline \multirow{2}{*}{$\frac{\text { Safety Population }}{\text { Event }}$} & \multicolumn{2}{|c|}{$\begin{array}{c}\text { TIW } \\
(\mathrm{N}=2,370)\end{array}$} & \multicolumn{3}{|c|}{$\begin{array}{c}\text { QW } \\
(\mathrm{N}=3,012)\end{array}$} \\
\hline & $\mathrm{N}$ & $\%$ & Event & $\mathrm{N}$ & $\%$ \\
\hline Fever & 135 & 5.7 & Granulocytopenia & 211 & 7.0 \\
\hline Granulocytopenia & 110 & 4.6 & Nausea & 181 & 6.0 \\
\hline Nausea & 101 & 4.3 & Fever & 173 & 5.7 \\
\hline Dyspnea & 97 & 4.1 & Fatigue/tiredness & 167 & 5.5 \\
\hline Asthenia & 81 & 3.4 & Dyspnea & 149 & 5.0 \\
\hline Vomiting & 80 & 3.4 & Vomiting & 132 & 4.4 \\
\hline Sepsis & 69 & 2.9 & Asthenia & 109 & 3.6 \\
\hline Fatigue/tiredness & 65 & 2.7 & Dehydration & 104 & 3.5 \\
\hline Dehydration & 63 & 2.7 & Pneumonia & 92 & 3.1 \\
\hline Pain & 59 & 2.5 & Pain & 85 & 2.8 \\
\hline Pneumonia & 56 & 2.4 & Sepsis & 74 & 2.5 \\
\hline
\end{tabular}

TIW= community study using thrice-weekly therapy;

QW=community study using once-weekly therapy.

injection that make QW administration statistically more costly. An EPO cost increase of $27 \%$ results in statistically significant higher total costs for QW patients.

\section{Discussion}

EPO-dosed TIW has been demonstrated previously to be cost effective for anemic cancer patients who are receiving chemotherapy with or without radiation therapy. ${ }^{10}$ The need for 3 office visits and 3 injections (intravenous infusions) each week, however, is often not feasible for some cancer patients, 


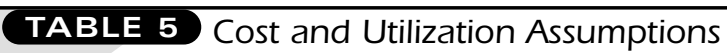

\begin{tabular}{|c|c|c|c|c|}
\hline Cost Item & Unit Price (\$) & Number of Units & Reference/Source & Comment \\
\hline Epoetin alfa (EPO) & 0.013356 & EPO units actually administered & $\begin{array}{l}\text { AWP, Drug Topics, Red Book, Medical } \\
\text { Economics, April } 2002\end{array}$ & \\
\hline \multicolumn{5}{|l|}{ Transfusion } \\
\hline Material and administrative costs & 549.76 & PRBC units transfused & $\begin{array}{l}\text { Cremieux et al. }(2000)^{23} \text {; CPI for } \\
\text { Medical Care Services }\end{array}$ & Adjusted for inflation \\
\hline Opportunity cost per hour & 14.65 & 8 hours per transfusion & $\begin{array}{l}\text { Cremieux et al. (1999); Average hourly } \\
\text { earnings of production workers } \\
\text { (BLS Series EES 00500006) }\end{array}$ & $\begin{array}{l}\text { Hours in therapy, } \\
\text { including travel }\end{array}$ \\
\hline \multicolumn{5}{|l|}{ Tests } \\
\hline Erythropoietin concentration & 148.34 & 1 per patient & $\begin{array}{l}\text { Sheffield et al. (1997); CPI for } \\
\text { Medical Care Services }\end{array}$ & $\begin{array}{l}\text { Both trial protocols required } \\
\text { a baseline measurement; } \\
\text { adjusted for inflation }\end{array}$ \\
\hline $\mathrm{CBC}$ & 96.80 & 1 per patient per week & $\begin{array}{l}\text { Sheffield et al. (1997); CPI } \\
\text { for Medical Care Services }\end{array}$ & Adjusted for inflation \\
\hline \multicolumn{5}{|l|}{ Time } \\
\hline Office visit & 35.94 & 1 visit per dosage administration & $\begin{array}{l}\text { Ingenix } 2002 \text { National Fee } \\
\text { Analyzer, 50th percentile amount for } \\
\text { CPT code 99211; CPI for Medical } \\
\text { Care Services }\end{array}$ & $\begin{array}{l}\text { All visits assumed to } \\
\text { occur in addition to any } \\
\text { other office visit; adjusted } \\
\text { for inflation }\end{array}$ \\
\hline Opportunity cost per hour & 14.65 & 1 hour per physician administration & $\begin{array}{l}\text { Cremieux et al. (1999); Average hourly } \\
\text { earnings of production workers } \\
\text { (BLS Series EES 00500006) }\end{array}$ & \\
\hline
\end{tabular}

BLS=Bureau of Labor Statistics; EES=Earnings and Employment Supplement; $C P I=$ Consumer Price Index; $C B C=$ complete blood count; $P R B C=$ packed red blood cells; $A W P=$ average wholesale price; $C P T=$ current procedural terminology.

caregivers, and the health care delivery systems. Now that a QW regimen has been shown to be equivalent in effectiveness to the TIW regimen, one would expect a switch to the equally effective yet substantially simpler regimen. ${ }^{4,6}$

Because the starting dose of the QW regimen necessitates $33 \%$ more of EPO per week, the clinical and logistical advantages of the QW regimen should also be assessed from the economic perspective. Our principal finding shows that the use of 1 EPO administration per week does not require any statistically significant incremental expense from a societal perspective when compared with a TIW regimen. These cost trade-offs need to be assessed individually. Further extension of dosing regimens to reduce potential medical visits, however, must have natural limits as to the increases in drug costs that are acceptable to achieve these reductions and still remain cost effective.

The results described in this analysis are based on the actual resource use incurred by patients while they remained enrolled in the clinical studies. One advantage of communitybased trial data is the availability of actual utilization and effectiveness measures obtained under standard (usual care) practices rather than the efficacy data determined from randomized controlled trials. ${ }^{15,16}$ Data for patients who discontinued study participation early (i.e., prior to the sixteenth treatment week) were evaluated up to the point of the patients' withdrawal, even though patients may have continued to incur costs and benefits. Nevertheless, the relative overall costs of patient treatment in TIW and QW are informative and demonstrate that the overall costs of QW dosing are similar to TIW dosing.

Several potential cost categories, not considered here because of limited data, may further increase the economic advantages of less-frequent dosing regimens. For example, caregiver time, which has been demonstrated to be an important cost driver in cancer care, was not included, even though patients may require assistance to travel to their providers' offices. ${ }^{22}$ Intangible costs, such as avoiding 2 additional injections every week (and avoiding the medical office altogether), have not been included and would make the QW regimen even more advantageous. Overall, however, the categories that were not considered are unlikely to significantly affect the relative costs reported in this study.

One potential implication of this analysis is that EPO regimens with administrations less frequent than once weekly may result in relatively small reductions in total treatment costs. Total time costs represented $18 \%$ of the total costs for the TIW regimen and 6\% for the QW regimen. Assuming that patients make office visits only when an EPO dose is scheduled, a once- 


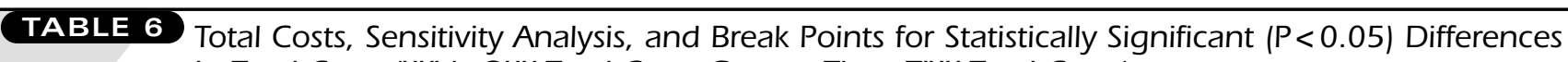
in Total Costs (With OW Total Costs Greater Than TIW Total Costs)

\begin{tabular}{|c|c|c|}
\hline & $\begin{array}{c}\text { TIW } \\
(\mathrm{N}=2,198)\end{array}$ & $\begin{array}{c}\text { QW } \\
(\mathrm{N}=2,856)\end{array}$ \\
\hline & Costs (2002 U.S. Dollars) & \\
\hline $\begin{array}{l}\text { Panel A: Costs } \\
\text { Total costs } \\
\text { 95\% CI } \\
\text { Epoetin alfa } \\
\text { 95\% CI } \\
\text { Laboratory tests } \\
\text { 95\% CI } \\
\text { Transfusions } \\
\text { 95\% CI } \\
\text { Time } \\
\text { 95\% CI }\end{array}$ & $\begin{array}{c}\$ 9,265 \\
(\$ 9,083-\$ 9,447) \\
\$ 5,474 \\
(\$ 5,350-\$ 5,598) \\
\$ 1,433 \\
(\$ 1,412-\$ 1,453) \\
\$ 650 \\
(\$ 591-\$ 709) \\
\$ 1,709 \\
(\$ 1,678-\$ 1,740)\end{array}$ & $\begin{array}{c}\$ 9,204 \\
(\$ 9,057-\$ 9,350) \\
\$ 6,725^{*} \\
(\$ 6,611-\$ 6,838) \\
\$ 1,350^{*} \\
(\$ 1,332-\$ 1,367) \\
\$ 538 \\
(\$ 489-\$ 587) \\
\$ 592^{*} \\
(\$ 583-\$ 600)\end{array}$ \\
\hline $\begin{array}{l}\text { Panel B: Sensitivity Analysis } \\
\text { Base case } \\
95 \% \text { CI } \\
\text { Epoetin costs increased by } 10 \% \\
95 \% \text { CI } \\
\text { Epoetin costs reduced by } 10 \% \\
95 \% \text { CI } \\
\text { Transfusion cost increased by } 10 \% \\
95 \% \text { CI } \\
\text { Transfusion cost reduced by } 10 \% \\
95 \% \text { CI } \\
\text { Opportunity cost at } \$ 0 \\
95 \% \text { CI } \\
\text { Opportunity cost at } \$ 30 \\
95 \% \text { CI } \\
\text { Physician fee at } \$ 5 \\
95 \% \text { CI } \\
\text { Physician fee at } 75 \text { th percentile ( } \$ 40.18 \text { ) } \\
95 \% \text { CI } \\
\text { Physician fee at } \$ 60 \\
95 \% \text { CI } \\
0.75 \text { Office visits per epoetin dose } \\
95 \% \text { CI }\end{array}$ & $\begin{array}{c}\$ 9,265 \\
(\$ 9,083-\$ 9,447) \\
\$ 9,813 \\
(\$ 9,619-\$ 10,006) \\
\$ 8,718 \\
(\$ 8,547-\$ 8,888) \\
\$ 9,324 \\
(\$ 9,139-\$ 9,508) \\
\$ 9,206 \\
(\$ 9,026-\$ 9,386) \\
\$ 8,711 \\
(\$ 8,538-\$ 8,883) \\
\$ 9,846 \\
(\$ 9,653-\$ 10,038) \\
\$ 8,220 \\
(\$ 8,053-\$ 8,386) \\
\$ 9,409 \\
(\$ 9,224-\$ 9,593) \\
\$ 10,078 \\
(\$ 9,883-\$ 10,273) \\
\$ 8,838 \\
(\$ 8,662-\$ 9,013)\end{array}$ & $\begin{array}{c}\$ 9,204 \\
(\$ 9,057-\$ 9,350) \\
\$ 9,876 \\
(\$ 9,718-\$ 10,003) \\
\$ 8,531 \\
(\$ 8,395-\$ 8,667) \\
\$ 9,253 \\
(\$ 9,104-\$ 9,401) \\
\$ 9,155 \\
(\$ 9,010-\$ 9,299) \\
\$ 8,983^{*} \\
(\$ 8,840-\$ 9,126) \\
\$ 9,435^{*} \\
(\$ 9,284-\$ 9,585) \\
\$ 8,842^{*} \\
(\$ 8,670-\$ 8,984) \\
\$ 9,253 \\
(\$ 9,106-\$ 9,400) \\
\$ 9,485^{*} \\
(\$ 9,335-\$ 9,635) \\
\$ 9,056 \\
(\$ 8,911-\$ 9,200)\end{array}$ \\
\hline & Total Costs (2002 U.S. Dollars) & \\
\hline $\begin{array}{l}\text { Panel C: Break Points for Statistically } \\
\text { Significant Differences in Total Costs } \\
(P<0.05), \text { QW Costs Higher Than TIW Costs }\end{array}$ & & \\
\hline $\begin{array}{l}\text { Epoetin costs increased by } 27 \% \text { (nearest } 1 \% \text { ) } \\
\text { Transfusion cost reduced by } \% \text { (N/A) } ¥ \\
\text { Opportunity cost at } \$ 2.00 \text { (nearest } \$ 0.50 \text { ) } \\
\text { Physician fee at } \$ 22.50 \text { (nearest } \$ 0.50 \text { ) } \\
0.74 \text { office visits per epoetin alfa dose (nearest } 1 \% \text { ) }\end{array}$ & $\begin{array}{l}\$ 10,743 \\
\mathrm{~N} / \mathrm{A} \\
\$ 8,786 \\
\$ 8,811 \\
\$ 8,821\end{array}$ & $\begin{array}{l}\$ 11,019 \\
\text { N/A } \\
\$ 9,013 \\
\$ 9,047 \\
\$ 9,050\end{array}$ \\
\hline
\end{tabular}

* Scenarios where QW is statistically different from TIW $(P<0.05)$ by 2-tailed $t$ test.

$¥$ Break point for statistical significance cannot be found.

$T I W=$ community study using thrice weekly therapy; $Q W=$ community study using once-weekly therapy; $C I=$ confidence interval. ${ }^{4,6}$

every-other-week regimen would result in time cost savings equal to 3\% (or 6\% for a 2-week period) of the QW regimen's total costs. Similarly, once-monthly dosing would result in time cost savings of $4.5 \%$ (or $18 \%$ for a 4 -week period) of the QW regimen's total costs. Less-frequent dosing may reduce time burdens on physicians, patients, and caretakers, and reduce the injections incurred by patients. However, because the cost of time relative to other costs is small, administrations less frequent than once weekly may reduce total costs by only small amounts. 


\section{Conclusion}

The cost-minimization analysis was based on data from 2 large, open-label, community-based clinical studies, which allowed the use of actual cost measures that would be incurred under customary care circumstances rather than those generally observed in a randomized controlled trial. Thus, the results obtained are likely to more accurately reflect actual clinical practice. In conjunction with earlier work establishing the similarity of clinical effectiveness, this research suggests that once-weekly EPO dosing for anemic cancer patients is a costeffective alternative to traditional thrice-weekly EPO dosing, with the potential for improved convenience.

\section{DISCLOSURES}

Funding for this study was provided by Ortho Biotech Products, L.P. and was obtained by authors Pierre Y. Crémieux, John M. Fastenau, and Catherine T. Piech. Fastenau and Piech are employed by Ortho Biotech and own Johnson \& Johnson stock; Crémieux and authors George Kosicki and A. Mark Fendrick are consultants to Ortho Biotech. This research was presented as an abstract and a poster at the annual summer meeting of the American Society of Health-System Pharmacists, San Diego, California, May 31 to June 4, 2003. Crémieux served as principal author of the study. Study concept and design were contributed by Crémieux, Fastenau, Piech, and Kosicki. Analysis and interpretation of data were contributed by Crémieux, Fastenau, Kosicki, and author A. Mark Fendrick. Statistical expertise and drafting of the manuscript were primarily the work of Crémieux and Kosicki; critical revision of the manuscript was the work of Fendrick, Piech, and Fastenau. Administrative, technical, and/or material support was provided by James Rosberg, manager, and Rym Ben-Hamadi, associate, Analysis Group, Inc., Boston, Massachusetts.

\section{REFERENCES}

1. Jilani SM, Glaspy JA. Impact of epoetin alfa in chemotherapy-associated anemia. Semin Oncol. 1998;25(5):571-76.

2. Cella D. The Functional Assessment of Cancer Therapy-Anemia (FACT-An) scale: a new tool for the assessment of outcomes in cancer anemia and fatigue. Semin Hematol. 1997;34(3 suppl 2):13-19.

3. Yellen SB, Cella DF, Webster K, Blendowski C, Kaplan E. Measuring fatigue and other anemia-related symptoms with the Functional Assessment of Cancer Therapy (FACT) measurement system. J Pain Symptom Manage. 1997;13(2): 63-74.

4. Demetri GD, Kris M, Wade J, Degos L, Cella D, for the Procrit Study Group. Quality-of-life benefit in chemotherapy patients treated with epoetin alfa is independent of disease response or tumor type: results from a prospective community oncology study. J Clin Oncol. 1998;16(10):3412-25.

5. Glaspy J, Bukowski R, Steinberg D, Taylor C, Tchekmedyian S, Vadhan-Raj S, for the Procrit Study Group. The impact of therapy with epoetin alfa on clinical outcomes in patients with nonmyeloid malignancies during cancer chemotherapy in community oncology practice. J Clin Oncol. 1997;15(3):1218-34.

6. Gabrilove JL, Cleeland CS, Livingston RB, Sarokhan B, Winer E, Einhorn LH. Clinical evaluation of once-weekly dosing of epoetin alfa in chemotherapy patients: improvements in hemoglobin and quality of life are similar to threetimes-weekly dosing. J Clin Oncol. 2001;19(11):2875-82.
7. Littlewood TJ, Bajetta E, Nortier JW, Vercammen E, Rapoport B. Effects of epoetin alfa on hematologic parameters and quality of life in cancer patients receiving nonplatinum chemotherapy: results of a randomized, double-blind, placebo-controlled trial. J Clin Oncol. 2001;19(11):2865-74.

8. Fallowfield L, Gagnon D, Zagari M, et al. Multivariate regression analyses of data from a randomized, double-blind, placebo-controlled study confirm quality of life benefit of epoetin alfa in patients receiving non-platinum chemotherapy. Br J Cancer. 2002;87(12):1341-53.

9. Crawford J, Cella D, Cleeland CS, et al. Relationship between changes in hemoglobin level and quality of life during chemotherapy in anemic cancer patients receiving epoetin alfa therapy. Cancer. 2002;95(4):888-95.

10. Rizzo JD, Lichtin AE, Woolf SH, et al. Use of epoetin in patients with cancer: evidence-based clinical practice guidelines of the American Society of Clinical Oncology and the American Society of Hematology. J Clin Oncol. 2002;20(19): 4083-107.

11. National Comprehensive Cancer Network, Cancer and Treatment-Related Anemia, Clinical Practice Guidelines, Version 2, 2004. Available at: http://www.nccn.org/professionals/physician_gls/PDF/anemia.pdf. Accessed July 19, 2004.

12. CMS Manual System, Publication 100-2, Medicare Benefit Policy Manual, Chapter 15, Section 50.5.2. Available at: http://www.medicarenhic.com/ cal_prov/lmrp/lmrp_01_111R6.htm. Accessed July 28, 2004.

13. Crawford J, Demetri GD, Gabrilove JL, Blasi MV, Sarokhan BJ, Glaspy J. Clinical benefits of epoetin alfa therapy in patients with lung cancer. Clin Lung Cancer. 2002;3(3):180-90.

14. Shasha D, George MJ, Harrison LB. Once-weekly dosing of epoetin alfa increases hemoglobin and improves quality of life in anemic cancer patients receiving radiation therapy either concomitantly or sequentially with chemotherapy. Cancer. 2003;98(5):1072-79.

15. Crémieux PY, Finkelstein SN, Berndt ER, Crawford J, Slavin MB. Costeffectiveness, quality-adjusted life-years and supportive care: recombinant human erythropoietin as a treatment of cancer-associated anaemia. Pharmacoeconomics. 1999;16(5, pt 1):459-72.

16. Sheffield R, Sullivan SD, Saltiel E, Nishimura L. Cost comparison of recombinant human erythropoietin and blood transfusion in cancer chemotherapy-induced anemia. Ann Pharmacother. 1997;31(1):15-22.

17. Barosi G, Marchetti M, Liberato NL. Cost-effectiveness of recombinant human erythropoietin in the prevention of chemotherapy-induced anaemia. Br J Cancer. 1998;78(6):781-87.

18. Ortega A, Dranitsaris G, Puodziunas ALV. What are cancer patients willing to pay for prophylactic epoetin alfa? A cost-benefit analyis. Cancer. 1998; 83(12):2588-96

19. Gold MR, Siegel JE, Russell LB, Weinstein MC, eds. Cost-Effectiveness in Health and Medicine. New York: Oxford University Press; 1996.

20. Schulman KA, Linas BP. Pharmacoeconomics: state of the art in 1997 Annu Rev Public Health. 1997;18:529-48.

21. Drug Topics Red Book. Montvale, NJ: Thomson Medical Economics; April 2002.

22. Hayman JA, Langa KM, Kabeto MU, et al. Estimating the cost of informal caregiving for elderly patients with cancer. J Clin Oncol. 2001;19:3219-25.

23. Crémieux PY, Barrett B, Anderson K, Slavin MB. Cost of outpatient blood transfusion in cancer patients. J Clin Oncol. 2000;18(14):2755-61. 